\title{
I don't want to go back: examining the return to physical workspaces during COVID-19.
}

\author{
LIU, Z., VAN EGDOM, D., FLIN, R., SPITZMUELLER, C., ADEPOJU, O. and \\ KRISHNAMOORTI, R.
}

This is the peer reviewed version of the following article: LIU, Z., VAN EGDOM, D., FLIN, R., SPITZMUELLER, C., ADEPOJU, O. and KRISHNAMOORTI, R. 2020. I don't want to go back: examining the return to physical workspaces during COVID-19. Journal of occupational and environmental medicine [online], 62(11), pages 953-958, which has been published in final form at https://doi.org/10.1097/JOM.0000000000002012. 
Paper in press Journal of Occupational and Environmental Medicine.

\section{Don't Want to Go Back: Examining the Return to Physical Workspaces \\ During COVID-19}

Zihan Liu, B.S.1- Drake van Egdom, M.A.1- Rhona Flin, Ph.D.2- Christiane Spitzmueller, Ph.D.1,3- Omolola Adepoju, M.P.H., Ph.D.4- Ramanan Krishnamoorti, Ph.D.5

${ }_{1}$ Department of Psychology, University of Houston, Houston, Texas

${ }_{2}$ Aberdeen Business School, Robert Gordon University, Aberdeen, Scotland

${ }_{3}$ Faculty of Business Administration, Memorial University of Newfoundland, St John's, Canada

${ }_{4}$ College of Medicine, University of Houston, Houston, Texas

${ }_{5}$ Department of Chemical and Biomolecular Engineering, University of Houston, Houston, Texas

Christiane Spitzmueller, Ph.D.

3695 Cullen Boulevard, Houston, TX, 77204. Phone: (281)-610-9099; Email:

cspitzmu@central.uh.edu

Funding Sources

None.

\section{Conflict of Interest}

None declared.

\section{Acknowledgement}

Support for this project was provided by UH Energy, Pink Petro, PESA and IPAA.

\section{Ethical Consideration \& Disclosure}

Data collection was approved by the University of Houston's Institutional Review Board (IRB\#s 02229). 


\begin{abstract}
Objective: We study employee perspectives on return to physical workspaces to ultimately inform employers' and policy makers' decision making around the return to work during COVID-19.
\end{abstract}

Methods: We tested the three-component conceptual model using survey data collected in the United States in May 2020 from samples of energy workers $(N=333)$.

Results: Females, non-Caucasians, and employees living in multi-generational households were less willing to return. Concerns about childcare were negatively related to willingness to return, whereas organizational strategies for mitigating COVID-19 transmission at work were positively related to willingness to return. COVID-19 infections in an employees' network were also negatively related to employees' willingness to return.

Conclusions: Blanket policies may miss the nuanced needs of different employee groups. Employers and policy makers should adopt flexible approaches to ensure a return to workspaces that addresses employee concerns and needs.

Keywords: return to work, COVID-19, energy industry, preventive measure 


\section{Don't Want to Go Back: Examining the Return to Physical Workspaces During COVID-19}

The coronavirus pandemic (COVID-19) has resulted in 12.9 million cases worldwide and over 500,000 deaths. ${ }^{1}$ In April and May 2020, many states and countries observed downward trends in new COVID-19 infections and hospitalizations, resulting in the easing of social and economic restrictions. ${ }^{2,3}$ In the United States (U.S.), this downward trend resulted in the relaxation of stay-at-home mandates and a resurgence of COVID-19 cases. This poses a challenge for employers as they navigate decisions around the return to physical workspaces for employees, many of which have been working from home since mid-March 2020.

Returning to the physical workplace is a priority, especially in industries in the energy sector. As of 2019, 6.7 million Americans worked in the energy industry accounting for $4.6 \%$ of the US workforce. ${ }^{4}$ However, since the onset of the pandemic, there has been a decline in oil prices and energy investment, ${ }^{5}$ resulting in over 600,000 layoffs happening in March and April. A considerable proportion of workers in the energy sector are often considered essential, as they must perform on-site instead of working from home. ${ }^{6}$ These individuals have no choice but to face the elevated risk for COVID-19 infection in going to their physical workspaces. For others able to work from home, a recent study found that 80 percent of respondents enjoyed working from home, with a majority of participants reporting equal, if not increased, productivity as they had before COVID-19. ${ }^{7}$

There are a variety of contributing factors that may play a role in a working individual's inclination to return to their physical workspace, including network exposure, strategies to control COVID-19 transmission, and unique individual considerations. Certain employees may experience a higher risk for COVID-19 contraction due to individual factors, including 
demographic, family, and health-related characteristics. For example, older individuals and people of color, especially African American and Hispanic individuals, have experienced higher rates of infection and mortality. ${ }^{8}$ Living in multi-generational households has been suggested to make individuals more vulnerable for infection, as multigenerational households are more likely to be crowded, making quarantining more difficult if one family member is infected. ${ }^{9}$ Healthrelated characteristics, like having underlying or pre-existing conditions, also increases one's risk for poor health outcomes with COVID-19 infection. Impacts of COVID-19 in individuals' networks may also play a part. Assuming models are accurate, more than 1.7 million Americans will lose a close kin, such as a parent, child, grandparent, or other close family member, with even more individuals experiencing a COVID-19 death in their broader networks. ${ }^{10}$ Deaths in kin relationships have negative outcomes for those closest to them, including physical and mental health ${ }^{11,12}$ and may influence their willingness to go back to the physical workspaces. All of these risk factors contribute to an employee's proclivity for returning to work while the pandemic is still occurring.

The return to physical worksites and offices represents an important policy decision with steep safety and health ramifications for organizations and employees. The US Centers for Disease Control and Prevention (CDC) updated interim guidance for workplaces in May, 2020, including suggestions on health checks and hazard assessments. ${ }^{13}$ Enforcing health scans, appropriate strategies for both symptomatic and asymptomatic infections, proper disinfection protocols, as well as providing sufficient personal protective equipment to employees, are all critical in transmission control. Additional recommended organizational strategies include provisions of extra occupational health services and adjustment of work patterns. ${ }^{14}$ Although advisories from medical ${ }^{15}$ and public health ${ }^{16}$ researchers largely inform return-to-work 
guidance, psychological research can supplement these directives by identifying psychological mechanisms that inform societal and organizational readiness. ${ }^{17}$ Policies should account for the perspectives of the employees who are affected by these policies to demonstrate concern for employees as key organizational stakeholders. ${ }^{18}$

Employees' willingness to return during COVID-19 is related to two important factors: their evaluation of the consequence of returning to work and their perception of the difficulty of returning. To better inform employers' and policy makers' decision making around the return to physical workspaces, we developed and tested a three-component conceptual model, as shown in Figure 1, consisting of individual and health factors, COVID-19 network exposure, and organizational strategies for limiting COVID-19 transmission to explain employees’ willingness to return.

\section{$<$ INSERT FIGURE 1 ABOUT HERE $>$}

For individual and health factors, we expect employees with vulnerabilities to COVID19, such as older workers, non-white workers and workers with pre-existing health conditions to be less willing to return to physical workspaces, based on higher COVID-19 death rates among older adults, minorities, and people with comorbidities. ${ }^{8,19,20}$ We also expect concerns about the health and welfare of family members to be relevant, as women, employees with childcare concerns, or those living in multi-generational households may be less willing to return.

COVID-19 impacts on employees' personal and professional networks are also expected to be important. Due to the transmission of COVID-19 in small-world social networks, ${ }^{21}$ we anticipate employees with COVID-19 cases in their close personal and professional networks to be less willing to return. Last, organizations' COVID-19 transmission control strategies, such as daily health scans, disinfection protocols, and provisions of personal protective equipment such 
as masks and sanitizers, may reduce the perceived risks associated with return to physical workspaces and positively relate to employees' willingness to return.

\section{Methods}

\section{Sample and procedures}

We partnered with industry associations in the energy sector to reach out to a large pool of energy workers and collect data via self-administered electronic surveys from employees working from home or taking unpaid time off $(N=333)$ during our data collection. Invitations were sent out by multiple industry associations via listserv so an exact response rate cannot be obtained. The survey was administered during a 2-week period between April 27th, 2020 and May 8th, 2020 via Qualtrics and included respondents that met the following criteria: a) respondents indicated agreements on the consent question; b) respondent response durations were longer than 2 minutes; c) respondents provided responses on the employment status question and willingness to return questions; d) only the first-time responses were kept if there were multiple responses from the same IP or email address. Participants were excluded if they continued to work in the physical workspaces or were laid off since COVID-19.

In general, participants came from multiple subsectors of the energy industry including, oil and gas, power and utilities with various job titles, such as electrical engineer, energy market analyst, safety specialist, quality engineer and oil and gas chemicals sales to increase its representativeness of the overall energy workforce. As shown in Table 1, we oversampled women and energy workers from racial minorities in order to be able to take into account these population with potential extra difficulty during COVID-19 and examine specific challenges facing the segments of the energy industry that are expected to grow in the future. This 
oversampling was done intentionally to ascertain adequate statistical power to investigate the relationship between ethnicity and outcomes of interest.

\section{Measures}

The survey content was developed in partnership with industry associations. Survey questionnaire included information on respondents' socio-demographic characteristics, individual health factors, social network exposure to COVID-19 and anticipated organizational transmission control strategies. The dependent variable of interest was respondents' willingness to return to workspaces and consists of five items $(\alpha=.73)$. The items in Figure 2 were reversecoded and an additional item ("If my workplace reopens for business in the next month, I will gladly return to work") was also included. Items were developed based on the extant research on workplace turnover and employee decisions to stay. ${ }^{22}$ Response scales ranged from 1 (strongly disagree) to 5 (strongly agree). Employees' willingness to return was calculated from the average score of the five items. To increase interpretability, employees' willingness to return were converted into an ordinal variable including three ordinal categories, i.e., "reluctant to return" (scores lower than 3), "neutral" (scores equal to 3), and "willing to return" (scores higher than 3). Independent variables included:

\section{Anticipated Organizational COVID-19 Transmission Control Strategies. For the}

anticipated organizational COVID-19 transmission control strategies, respondents indicated the anticipated likelihood that their employer would use the organizational strategy to control COVID-19 infection. The strategies included daily health scans, disinfection protocols, discouragement of presenteeism, and provisions of personal protective equipment. Response scales ranged from 1 (strongly disagree) to 5 (strongly agree). 
Network Exposure to COVID-19. Three items were used to measure the extent to which individuals in an employees' personal or work network were infected, hospitalized, or died due to COVID-19 $(\alpha=.70)$. Sample items include, "Someone I am close to has been hospitalized with symptoms." Response scales ranged from 1 (strongly disagree) to 5 (strongly agree).

Demographic Information. Participants completed items pertaining to their gender, age, ethnicity, partner work hours, number of children, childcare concerns, living situation, and preexisting conditions $(0=$ none, $1=$ obesity, cardiovascular disease, diabetes, chronic lung disease, chronic kidney disease, or other diseases).

\section{Analysis}

All data management and analyses were performed using SPSS 26.0. Descriptive analyses, including frequencies, proportions, means and standard deviations, were used to describe the sample characteristics. We conducted ordinal logistic regression analysis to determine the extent to which the proposed individual and organizational independent variables significantly predicted employee willingness to return. This project was approved by the university institutional review board in April 2020.

\section{$<$ INSERT TABLE1 ABOUT HERE $>$}

\section{Results}

\section{Perspectives on Return to Work}

Employees expressed limited willingness to return to the workplace as shown in Figure 2, with $63.4 \%$ of the sample expressing a preference for not returning yet and a substantial portion $(71.2 \%)$ saying they would choose to continue to work from home if given the choice. $20.7 \%$ of the energy workers preferred unpaid time off over returning with a small percentage (4.8\%), 
indicating they would quit if forced to go back to their workplaces. These results reveal a phenomenon of reluctant returning, where people may feel forced to return to workspaces.

$<$ INSERT FIGURE 2 ABOUT HERE $>$

Regression analyses were used to investigate variables influencing employees’ willingness to return. Table 2 provides the results of the ordinal regression analyses.

$<$ INSERT TABLE 2 ABOUT HERE $>$

\section{Individual and Health Factors}

Employee demographic background was found to exert influence on their willingness to return to physical workspaces. Non-white employees $(B=-0.60, p=.020, \mathrm{OR}=0.55)$ and female employees $(B=-0.67, p=.010, \mathrm{OR}=0.51)$ were less willing to return to workspaces, consistent with the expectations. In contrast, employee age positively predicted their willingness to return $(B=0.02, p=.049, \mathrm{OR}=1.02)$. Living in a multi-generational household was negatively related to willingness to return $(B=-0.68, p=.078, \mathrm{OR}=0.51)$. Pre-existing health conditions were not significantly related to willingness to return for employees $(B=0.14, p$ $=.581, \mathrm{OR}=1.15)$. Supplemental analyses on the pre-existing conditions that are more closely related to COVID-19 also revealed that pre-existing chronic lung disease was not significantly related to willingness to return to work $(B=0.12, p=.783, \mathrm{OR}=1.12)$, probably due to limited power (i.e., only a small proportion of people endorsed that they had such pre-existing conditions).

We conducted additional analyses to investigate the importance of childcare for employees' return to physical workspaces. For employees with children under 18 years old $(N=$ 118), childcare concerns were negatively related to willingness to return $(B=-0.36, p=.011$, OR $=0.70$ ) after controlling for age, gender, number of children and partner work hours. In sum, 
these findings supported our framework that individual factors may contribute to employee willingness to return.

\section{COVID-19 Network Exposure}

Network exposure to COVID-19 was significantly related to employees' willingness to return $(B=-0.47, p=.002, \mathrm{OR}=0.62)$. When employees have someone in their close personal network or professional network infected by COVID-19, they are likely to develop an enhanced understanding of the severity of the illness, and hence be less likely to want to risk workplacebased transmission through returning to their physical workspace.

\section{Organizational COVID-19 Transmission Control Strategies}

Organizational strategies to limit the infection of COVID-19 can help alleviate people's unwillingness to return. Specifically, anticipated organizational provision of personal protective equipment (PPE) was positively associated with willingness to return $(B=0.36, p=.005, \mathrm{OR}=$ 1.44). Disinfection protocols $(B=0.16, p=.247, \mathrm{OR}=1.17)$, health scan questionnaires $(B=$ $0.19, p=.151, \mathrm{OR}=0.83)$ and compensation policies limiting attendance by sick employees $(B=$ $-0.09, p=.385, \mathrm{OR}=0.92$ ) were not related to willingness to return.

\section{Discussion}

Our research suggests that employees are moderately reluctant to return to workspaces. The results supported our conceptual model: individual and health factors, COVID-19 impacts, and organizational policies to mitigate COVID-19 transmission relate to willingness to return. Our results inform policies for the return to physical offices, which is continuing throughout the United States and other countries. Our study lays the foundation for future research to examine the dynamics of decisions around returning to physical workspaces, but further emphasizes the need to examine the effectiveness of these policies for different demographics, especially gender 
and ethnicity. For instance, organizations may need to provide more flexible arrangements related to return to work for minority groups, as the risk of severe illness from COVID-19 has been found to be disparate for minority employees in the U.S. ${ }^{23}$ Similar patterns were also found in other countries. For example, the UK Office of National Statistics has reported that in England and Wales, even after accounting for differences in age, sex, geography and self-reported health and disability factors, Black people are still twice as likely to die from the virus, and individuals of Bangladeshi, Pakistani, Indian and mixed ethnicity also have a high risk of death compared with the white population. ${ }^{24}$ Consequently, legal experts in the UK are now advising employers 'to risk-assess every employee's position on an individual basis. Taking an individual approach should also help to mitigate the risk of discrimination complaints from non-BAME [Black, Asian, Ethnic minority] employees ${ }^{25}$ Our study further highlights the need to provide ethnic minority employees and caregivers supplemental flexibility in managing their return to physical workspaces. However, in order to fully consider the subpopulation with potential extra difficulty during the COVID-19 period, the study oversampled female workers and workers from minority groups. Hence, we recommend the results be replicated and extended in future research.

This study further supports the importance of assessing employee well-being during COVID-19 ${ }^{26,27}$ as these factors may influence employees' psychological health after returning to work. ${ }^{28}$ Further, our findings may contribute to subsequent discussions around return to workspaces if second waves of COVID-19 infections reoccur. ${ }^{29,30}$

Organizations and regulatory bodies should develop workplace policies that account for demographic factors. Differences in susceptibility to infection and death, particularly among minority workers, should be considered and separate. Flexible policies will likely be required to meet the needs and concerns of minority employees and those living in multi-generational 
households. In addition, provisions of personal protective equipment, including sanitizer and masks, will likely mitigate employees' concerns. Considering that old people are usually at higher risks and the unexpected finding in this study that older employees are slightly more willing to return, it becomes even more important for organizations to provide necessary supplies to those vulnerate employees to ensure their safety at work. Even if securing equipment is difficult, supplying personal protective equipment should be a critical component to an organization's return to physical workspace policy, especially if employees are in direct contact with customers or members of the public. ${ }^{31}$ Further, providing resources to address a lack of safe and reliable childcare might reduce psychological resistance to return among those with children. ${ }^{32}$ Last, organizational analyses of workplace hazards should include job conditions and transmission prevention that enhance employee willingness to return. 


\section{References}

1. Johns Hopkins Coronavirus Resource Center. COVID-19 Case Tracker. Available at: https://coronavirus.jhu.edu. Accessed July 10, 2020.

2. Johns Hopkins Coronavirus Resource Center. America Is Reopening. But have we flattened the curve? Available at: https://coronavirus.jhu.edu/data/new-cases-50-states. Accessed July $10,2020$.

3. Johns Hopkins Coronavirus Resource Center. New Cases of COVID-19 In World Countries. Available at: https://coronavirus.jhu.edu/data/new-cases. Accessed July 10, 2020.

4. National Association of State Energy Officials \& Energy Futures Initiative. 2019 U.S. Energy and Employment Report (USEER). Available: https://www.usenergyjobs.org/2019report. Accessed July 14, 2020.

5. International Energy Agency. World Energy Investment 2020 - Analysis. May, 2020. Available at: https://www.iea.org/reports/world-energy-investment-2020/key-findings. Accessed July 14, 2020.

6. National Conference of State Legislatures. COVID-19: Essential Workers in the States. May 21, 2020. Available at: https://www.ncsl.org/research/labor-and-employment/covid-19essential-workers-in-the-states.aspx. Accessed July 14, 2020.

7. Boland B, De Smet A, Palter R, Sanghvi A. Reimagining the Office and Work Life after COVID-19. June 8, 2020. Available at: https:/www.mckinsey.com/businessfunctions/organization/our-insights/reimagining-the-office-and-work-life-after-covid-19\#. Accessed July 14, 2020.

8. Aldridge RW, Lewer D, Katikireddi SV, et al. Black, Asian and Minority Ethnic groups in England are at increased risk of death from COVID-19: indirect standardisation of NHS 
mortality data. Wellcome Open Res. 2020;5:88. doi:10.12688/wellcomeopenres.15922.1

9. Francis L. Why Some Families Are Hit So Hard By COVID-19. Fatherly. June 8, 2020. Available at: https:/www.fatherly.com/news/why-some-families-are-hit-so-hard-by-covid19. Accessed July 14, 2020.

10. Verdery AM, Smith-Greenaway E, Margolis R, Daw J. Tracking the reach of COVID-19 kin loss with a bereavement multiplier applied to the United States. Proc Natl Acad Sci. Published online July 10, 2020:202007476. doi:10.1073/pnas.2007476117

11. Fletcher J, Vidal-Fernandez M, Wolfe B. Dynamic and heterogeneous effects of sibling death on children's outcomes. Proc Natl Acad Sci. 2018;115(1):115-120.

12. Elwert F, Christakis NA. The effect of widowhood on mortality by the causes of death of both spouses. Am J Public Health. 2008;98(11):2092-2098.

13. Centers for Disease Control and Prevention. Coronavirus Disease 2019 (COVID-19) Interim Guidance for Businesses and Employers. February 11, 2020. Available at: https:/www.cdc.gov/coronavirus/2019-ncov/community/guidance-business-response.html. Accessed May 21, 2020.

14. Yang C-C, Chuang H-Y. The Strategy for Return to Work after the COVID-19 Pandemic on Small and Medium-sized Enterprises. J Occup Environ Med. 2020;Publish Ahead of Print. doi:10.1097/JOM.0000000000001926

15. Berenbaum MR. PNAS and the pandemic. Proc Natl Acad Sci. 2020;117(18):9650-9651. doi:10.1073/pnas.2006488117

16. Wells CR, Sah P, Moghadas SM, et al. Impact of international travel and border control measures on the global spread of the novel 2019 coronavirus outbreak. Proc Natl Acad Sci. 2020;117(13):7504-7509. doi:10.1073/pnas.2002616117 
17. Bavel JJV, Baicker K, Boggio PS, et al. Using social and behavioural science to support COVID-19 pandemic response. Nat Hum Behav. 2020;4(5):460-471. doi:10.1038/s41562020-0884-z

18. Smith A. What to Do When Scared Workers Don't Report to Work Due to COVID-19. April 20, 2020. Available at: https://www.shrm.org/resourcesandtools/legal-andcompliance/employment-law/pages/coronavirus-when-scared-workers-do-not-report-towork.aspx. Accessed July 10, 2020.

19. Jordan RE, Adab P, Cheng KK. Covid-19: risk factors for severe disease and death. BMJ. 2020;368. doi:10.1136/bmj.m1198

20. Liu K, Chen Y, Lin R, Han K. Clinical features of COVID-19 in elderly patients: A comparison with young and middle-aged patients. J Infect. 2020;80(6):e14-e18. doi:10.1016/j.jinf.2020.03.005

21. Weeden K, Cornwell B. The Small-World Network of College Classes: Implications for Epidemic Spread on a University Campus. Sociol Sci. 2020;7:222-241. doi:10.15195/v7.a9

22. Hom PW, Mitchell TR, Lee TW, Griffeth RW. Reviewing employee turnover: Focusing on proximal withdrawal states and an expanded criterion. Psychol Bull. 2012;138(5):831-858. doi: $10.1037 / \mathrm{a} 0027983$

23. Raifman MA, Raifman JR. Disparities in the Population at Risk of Severe Illness From COVID-19 by Race/Ethnicity and Income. Am J Prev Med. 2020;59(1):137-139. doi:10.1016/j.amepre.2020.04.003

24. Office for National Statistics. Coronavirus (COVID-19) related deaths by ethnic group, England and Wales. June 19, 2020. Available at: https://www.ons.gov.uk/peoplepopulationandcommunity/birthsdeathsandmarriages/deaths/ar 
ticles/coronaviruscovid19relateddeathsbyethnicgroupenglandandwales/latest. Accessed July $10,2020$.

25. Paida Dube. How can businesses protect BAME employees returning to work? People Management. June 16, 2020. Available at:

https:/www.peoplemanagement.co.uk/experts/legal/how-can-businesses-protect-bameemployees-returning-to-work. Accessed July 10, 2020.

26. Rudolph C, Allan B, Clark M, et al. Pandemics: Implications for Research and Practice in Industrial and Organizational Psychology. PsyArXiv; 2020. doi:10.31234/osf.io/k8us2

27. Rajkumar RP. COVID-19 and mental health: A review of the existing literature. Asian J Psychiatry. 2020;52:102066. doi:10.1016/j.ajp.2020.102066

28. Tan W, Hao F, McIntyre RS, et al. Is returning to work during the COVID-19 pandemic stressful? A study on immediate mental health status and psychoneuroimmunity prevention measures of Chinese workforce. Brain Behav Immun. Published online April 23, 2020. doi:10.1016/j.bbi.2020.04.055

29. Leung K, Wu JT, Liu D, Leung GM. First-wave COVID-19 transmissibility and severity in China outside Hubei after control measures, and second-wave scenario planning: a modelling impact assessment. The Lancet. 2020;395(10233):1382-1393. doi:10.1016/S0140$6736(20) 30746-7$

30. Xu S, Li Y. Beware of the second wave of COVID-19. The Lancet. 2020;395(10233):13211322. doi:10.1016/S0140-6736(20)30845-X

31. Occupational Safety and Health Administration. Guidance on preparing workplaces for COVID-19. Available at: https://www.osha.gov/Publications/OSHA3990.pdf. Accessed July 10, 2020. 
32. Kossek EE, Nichol V. The effects of on-site child care on employee attitudes and performance. Pers Psychol. 1992;45(3):485-509. doi:10.1111/j.1744-6570.1992.tb00857.x 


\section{Figure 1}

Conceptual Framework of Factors Influencing Employee Willingness to Return to Physical Workspaces during COVID-19

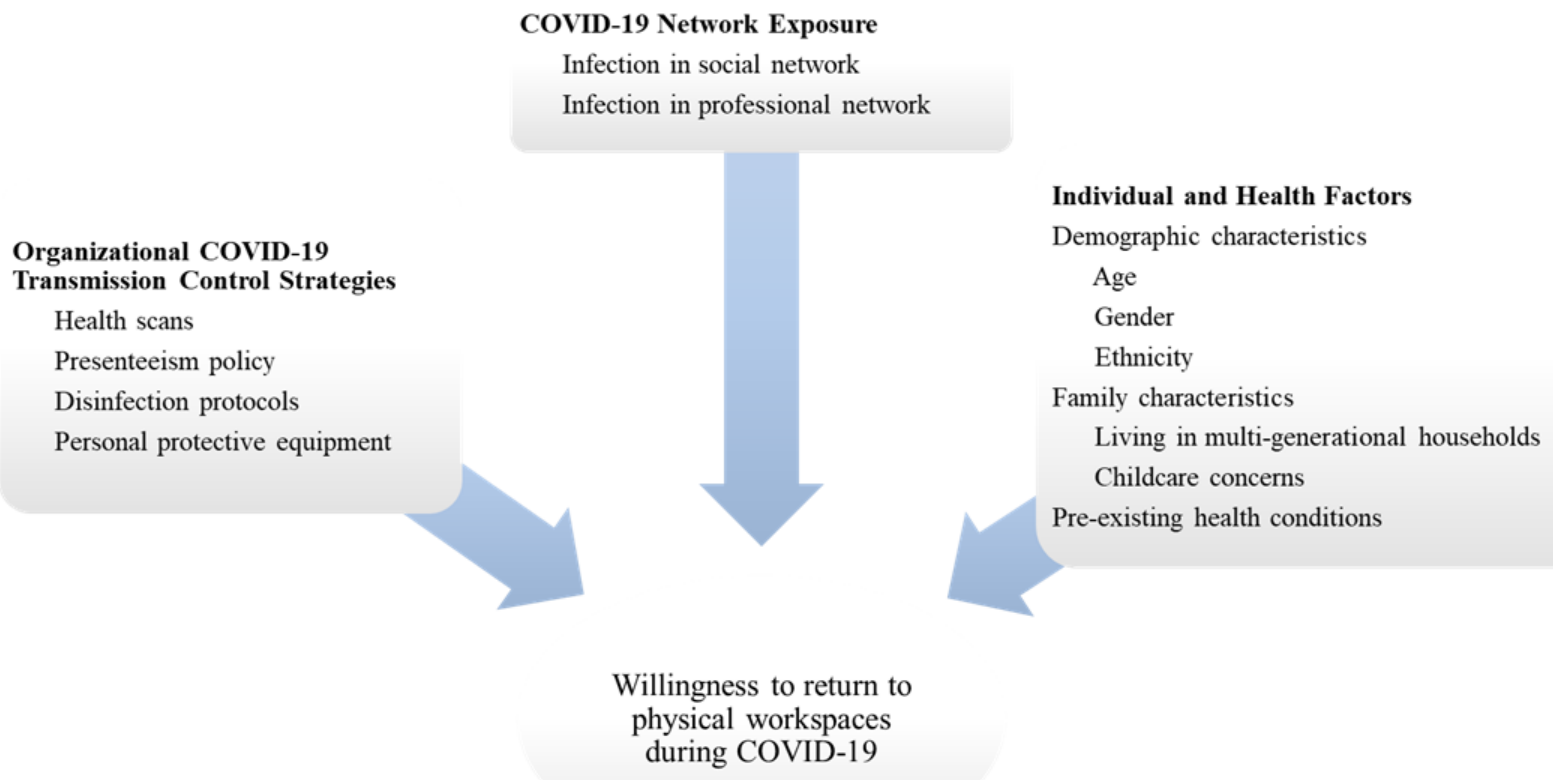


Figure 2

Employee Perspectives on Return to Physical Workspaces

"If my workplace reopens for business in the next month, I..."

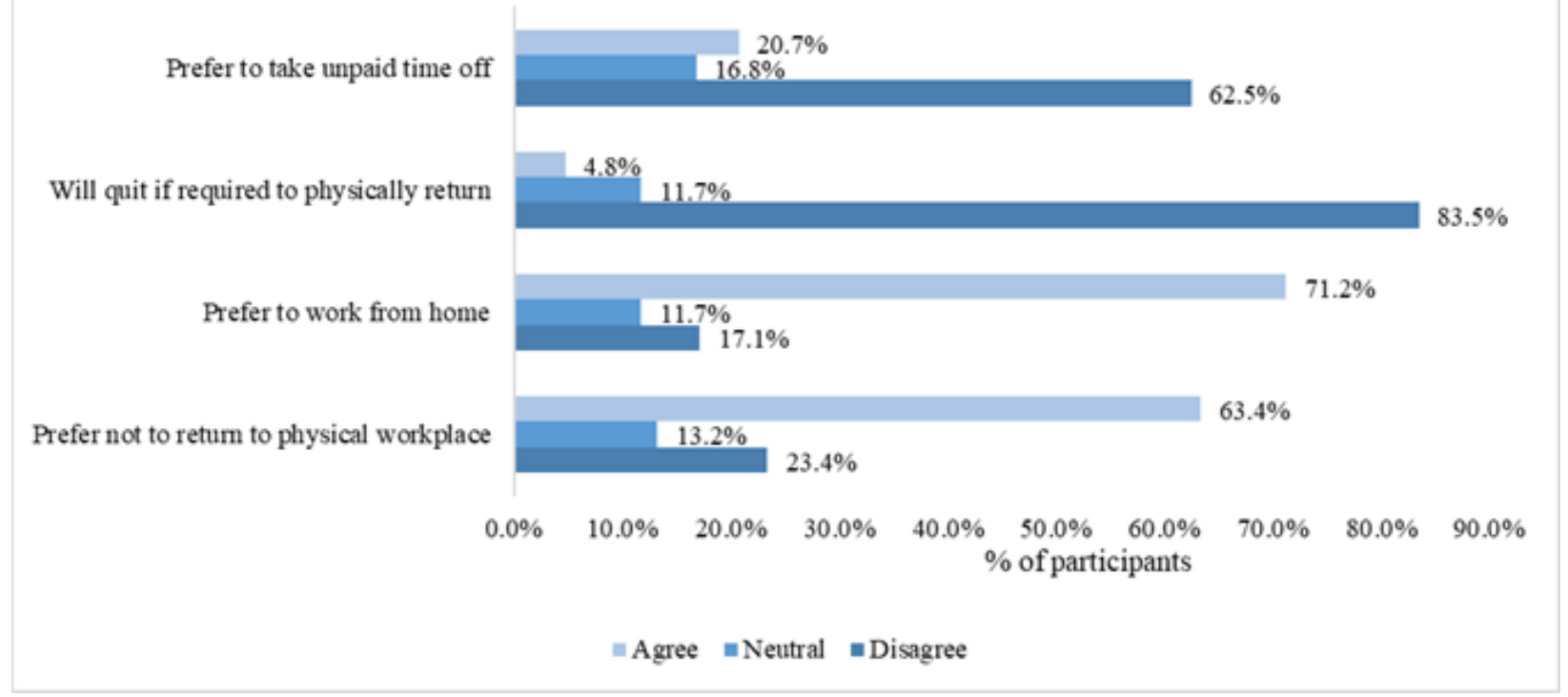

Note. Response scales ranged from 1 (strongly disagree) to 5 (strongly agree). To increase interpretability, "Strongly agree" and "Agree" were combined into "Agree," and "Strongly disagree" and "Disagree" were combined into "Disagree" in this figure. 
Table 1

Characteristics of the Current Sample

\begin{tabular}{|c|c|c|c|c|}
\hline Variable & Mean & $S D$ & $N$ & $\%$ \\
\hline Age & 42.43 & 13.13 & & \\
\hline Industry Tenure & 13.71 & 11.32 & & \\
\hline \multicolumn{5}{|l|}{ Gender } \\
\hline Male & & & 115 & 39.1 \\
\hline Female & & & 178 & 60.5 \\
\hline Other & & & 1 & 0.3 \\
\hline \multicolumn{5}{|l|}{ Ethnicity } \\
\hline Caucasian & & & 170 & 51.1 \\
\hline African American & & & 23 & 6.9 \\
\hline Hispanic or Latino & & & 32 & 9.6 \\
\hline Asian & & & 41 & 12.3 \\
\hline Other & & & 12 & 3.6 \\
\hline Prefer not to say & & & 55 & 16.5 \\
\hline Partner working hours per week & 26.07 & 20.42 & & \\
\hline \multicolumn{5}{|l|}{ Number of children } \\
\hline 0 & & & 165 & 57.9 \\
\hline 1 & & & 61 & 21.4 \\
\hline 2 & & & 48 & 16.8 \\
\hline 3 & & & 8 & 2.8 \\
\hline 4 & & & 3 & 1.1 \\
\hline \multicolumn{5}{|c|}{ Living in multi-generational households } \\
\hline Yes & & & 33 & 9.9 \\
\hline No & & & 300 & 90.1 \\
\hline \multicolumn{5}{|l|}{ Pre-existing conditions } \\
\hline Obesity & & & 50 & 15.0 \\
\hline Cardiovascular disease & & & 37 & 11.1 \\
\hline Diabetes & & & 12 & 3.6 \\
\hline Chronic lung disease & & & 26 & 7.8 \\
\hline Chronic kidney disease & & & 0 & 0 \\
\hline Other diseases & & & 28 & 8.4 \\
\hline
\end{tabular}


Table 2

Ordinal Logistic Regression Analysis Results for Willingness to Return to Physical Workspaces

\begin{tabular}{|c|c|c|c|}
\hline Parameter & $S E$ & OR & $\begin{array}{c}95 \% \mathrm{CI} \text { for } \\
\mathrm{OR}\end{array}$ \\
\hline
\end{tabular}

\begin{tabular}{lcccc}
\hline Individual and health factors & & & & \\
Gender & $-0.67^{*}$ & 0.26 & 0.51 & $0.31,0.85$ \\
Age & $0.02^{*}$ & 0.01 & 1.02 & $1.00,1.04$ \\
Ethnicity & $-0.60^{*}$ & 0.26 & 0.55 & $0.33,0.91$ \\
Pre-existing health conditions & 0.14 & 0.26 & 1.15 & $0.69,1.92$ \\
Living in multi-generational households & $-0.68^{\dagger}$ & 0.39 & 0.51 & $0.24,1.08$ \\
COVID-19 Network exposure & & & & \\
Network exposure to COVID-19 & $-0.47^{* *}$ & 0.15 & 0.62 & $0.46,0.84$ \\
Organizational COVID-19 transmission & & & & \\
$\quad$ Health scans & -0.19 & 0.13 & 0.83 & $0.65,1.07$ \\
Discouragement of presenteeism & -0.09 & 0.10 & 0.92 & $0.76,1.11$ \\
Disinfection protocols & 0.16 & 0.14 & 1.17 & $0.90,1.52$ \\
Provisions of personal protective equipment & $0.36^{* *}$ & 0.13 & 1.44 & $1.12,1.85$ \\
Cox and Snell pseudo $R^{2}$ & & 0.14 & \\
\hline
\end{tabular}

Note: $N=280 . \mathrm{SE}=$ standard error. $\mathrm{OR}=$ odds ratio. $\mathrm{CI}=$ confidence interval. Gender was coded as $0=$ male, $1=$ female. Ethnicity was coded as $0=$ Caucasians, $1=$ non-Caucasians. Preexisting health conditions were coded as $0=$ none, $1=$ obesity, cardiovascular disease, diabetes, chronic lung disease, chronic kidney disease or other diseases.

${ }^{\dagger} p<.10 ;{ }^{*} p<.05 ;{ }^{* *} p<.01$ (Wald tests). 